\title{
Frozen hydatid cysts can replace incineration and sterilize cysts
}

\author{
Kouidri Mokhtaria ${ }^{1, *}$ and Selles Sidi Mohammed Ammar ${ }^{1,2}$ \\ ${ }^{1}$ Laboratory of Parasitology of the Veterinary Institute, Ibn Khaldoun University, P.O. Box 78, Zaaroura Tiaret, Algeria \\ ${ }^{2}$ Laboratory of Research on Local Animal Products, Ibn Khaldoun University, P.O. Box 78, Zaaroura Tiaret, Algeria
}

\begin{abstract}
In many countries of Mediterranean area, abattoirs are not equipped with incinerators. This led us to find an alternative that may be the freezing of organs before they are thrown into landfills. In this sense, the aim of this study was to evaluate the scolicidal effect of refrigeration at $4^{\circ} \mathrm{C}$ and freezing at $-18^{\circ} \mathrm{C}$. Different refrigeration times $(24$ and $48 \mathrm{~h})$ and freezing times $\left(3,6\right.$, and $9 \mathrm{~h}$ ) have been used in triplicate. Refrigeration at $4^{\circ} \mathrm{C}$ was not sufficient to completely kill protoscolex. For $24 \mathrm{~h}$, the mortality rate did not exceed $44.44 \%$. After $48 \mathrm{~h}$, mortality rates varied from $20.13 \%$ to $65.49 \%$. The freezing at $-18{ }^{\circ} \mathrm{C}$ for $3 \mathrm{~h}$ remained insufficient to kill all protoscoleces although the mortality rate increased to $87.28 \%$. However, freezing at $-18{ }^{\circ} \mathrm{C}$ for 6 and $9 \mathrm{~h}$ has been found to be very effective in killing all protoscoleces present in the hydatid liquids. The present study demonstrates that freezing organs seized for hydatidosis at $-18^{\circ} \mathrm{C}$ for at least $6 \mathrm{~h}$ may be an alternative to incineration and will sterilize hydatid cysts before they are dumped. Keywords: Freezing, Hydatidosis, Scolicidal, Slaughterhouse.
\end{abstract}

\section{Introduction}

Echinococcosis is a cosmopolitan antropozoonosis common to both humans and mammal species. The disease results from the development of the larval or hydatid form of the canine tenia, E. granulosus sensu lato (s.1.) (Hasbi and Slioui, 2017). It is one of the most important zoonotic diseases in the world and is currently among the five most frequently diagnosed zoonoses in the Mediterranean (Sadjjadi, 2006; Dakkak, 2010). In Algeria, it is endemic in humans, with an annual incidence ranging from 1.78 to 2.26 per 100,000 humans (Benchikh El-Fegoun et al., 2016).

Several studies have shown that hydatidosis is a growing concern for public and socio-economic health. It is currently considered to be an emerging or reemerging disease and the geographical distribution and extent is greater than previously thought (Thompson and McManus, 2002; Torgerson et al., 2003; Moro and Schantz, 2009; Dakkak, 2010).

Theoretically, it is an eradicable disease but many factors are involved in maintaining the cycle, including behavioral and cultural factors are often difficult to regulate or modify (Dakkak, 2010).

In Algeria, the main factor influencing the persistence of the E. granulosus (s.1.) cycle is the contamination of dogs after ingestion of viscera of herbivores containing hydatid cysts (Kohil et al., 2017). Thus, the prevalence of stray dogs infested with E. granulosus (s.1.) ranged from $16 \%$ to $42 \%$ (Bentounsi et al., 2009; Benchikh ElFegoun et al., 2016). Generally, in many Mediterranean countries, slaughterhouses and mainly those in rural areas are inadequately equipped and frequently accessed by stray dogs (Dakkak, 2010), and the unavailability of incinerators in all slaughterhouses poses a problem of sterilization of seized viscera (Aoun and Bouratbine, 2007). The absence of incinerators, because of lack of means or because these slaughterhouses are located in the center of urban areas, and where the presence of incinerators is a source of pollution, led us to find an alternative that can be the freezing of the organs before that they be thrown into landfills. The objective of this study was to evaluate the scolicidal effect of refrigeration at $4^{\circ} \mathrm{C}$ and freezing at $-18^{\circ} \mathrm{C}$.

\section{Material and Methods}

\section{Hydatid cysts}

Hydatid cysts were collected from the liver and lungs of naturally infected sheep that had been slaughtered in Tiaret abatoir, Algeria.

For each experiments, hydatid cysts used for this study were those located on the same organ. The fertility of the liquid and the viability of protoscolex of hydatid cyst used as a control were verified according to the following technique:

\section{Fertility of the hydatid liquid}

The hydatid liquids were incised and the liquids recovered in sterile containers. After a few minutes, a drop of the sediment was placed between slide and coverslip and observed under an optical microscope (10×) (Daryani et al., 2009).

\section{Viabilty test}

The viability of protoscoleces was only performed for fertile hydatid fluids, according to the technique of Scala et al. (2006) slowly modified. One mililitre of sediment was added to equal volume of eosin $(0.2 \%)$. After a $15 \mathrm{~min}$ of incubation at room temperature. The remaining pellet of protoscoleces was then smeared on a glass slide, covered with a cover glass and examined 
under a light microscope. After exposure to the stain, dead protoscoleces absorbed eosin and colored red, but a live protoscoleces remained colorless and showed characteristic muscular movements and flame cell activity (Fig. 1).One cyst with a higher viabilty rate was considered as a control. Two hydatid cysts were kept at $4^{\circ} \mathrm{C}$ and their mortality rates of protoscoleces were determined after refrigeration during 24 and $48 \mathrm{~h}$. The three other cysts were frozen separately at $-18^{\circ} \mathrm{C}$, for 3,6 , and $9 \mathrm{~h}$. All tests were carried out in triplicate.

Determination of viability rate after refrigeration and freezing

The other hydatid cysts (from the same seizure) were separately, refrigerated at $4{ }^{\circ} \mathrm{C}$ during 24 and $48 \mathrm{~h}$ and frozen at $-18{ }^{\circ} \mathrm{C}$ for 3,6 , and $9 \mathrm{~h}$.

At the end of freezing, each case was allowed to thaw and the mortality rate was determined for each case.

The mortality rate of protoscoleces was calculated using the following formula:

$$
\text { Mortality Rate }(\%)=\frac{(\text { Number of dead protoscoleces })}{(\text { Total number of protoscoleces })} \times 100
$$

\section{Results}

In the light of Table 1, it is found that during different experiments, refrigeration at $4{ }^{\circ} \mathrm{C}$ for $24 \mathrm{~h}$ did not show high mortality rates, since the following rates were recorded; $44.44 \%, 12.98 \%$, and $23.05 \%$, respectively (Fig. 2).

In addition, $48 \mathrm{~h}$ of refrigeration at $4^{\circ} \mathrm{C}$ was not sufficient to completely kill protoscoleces and the mortality rate did not exceed $65.49 \%$. However, The motility of viable protoscolex has been well preserved (Fig. 3).

Thus, freezing at $-18^{\circ} \mathrm{C}$ for $3 \mathrm{~h}$ remained insufficient to kill all protoscoleces although the mortality rate varied from $30.44 \%$ to $87.28 \%$. The motility of some viable protoscoleces remained positive despite this freezing $\left(-18{ }^{\circ} \mathrm{C}\right.$ for $\left.3 \mathrm{~h}\right)$ (Fig. 4$)$.

In contrast, freezing at $-18^{\circ} \mathrm{C}$ for 6 and $9 \mathrm{~h}$ was found to be very effective in killing all protoscoleces present in the hydatid fluids, which showed $100 \%$ of mortality rates (Figs. 5 and 6).

\section{Discussion}

Hydatidosis is a serious medical and veterinary problem in many countries, particularly those with rural communities (Almalki et al., 2017). A number of factors have been found to influence the frequency and intensity of canine echinococcosis. The most important of these is the potential access that dogs have to uncooked and infected offal (Otero-Abad and Torgerson, 2013).

Through this study, it was found that during different times, refrigeration at $4^{\circ} \mathrm{C}$ was not sufficient to completely kill protoscoleces and that the mortality rate did not exceed $65.49 \%$. Thus, the motility of

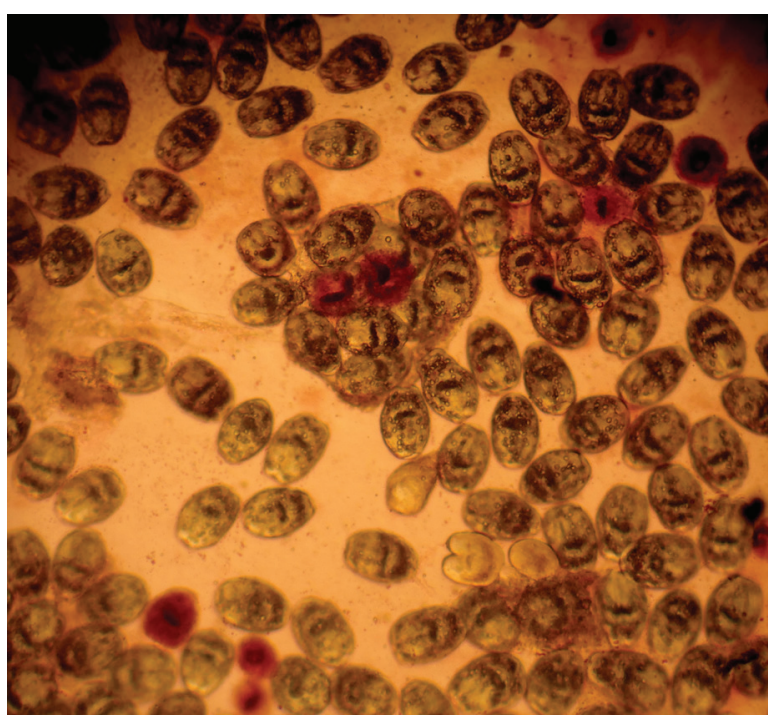

Fig. 1. Eosin staining technique, dead protoscoleces were stained red $(64 \times)$.

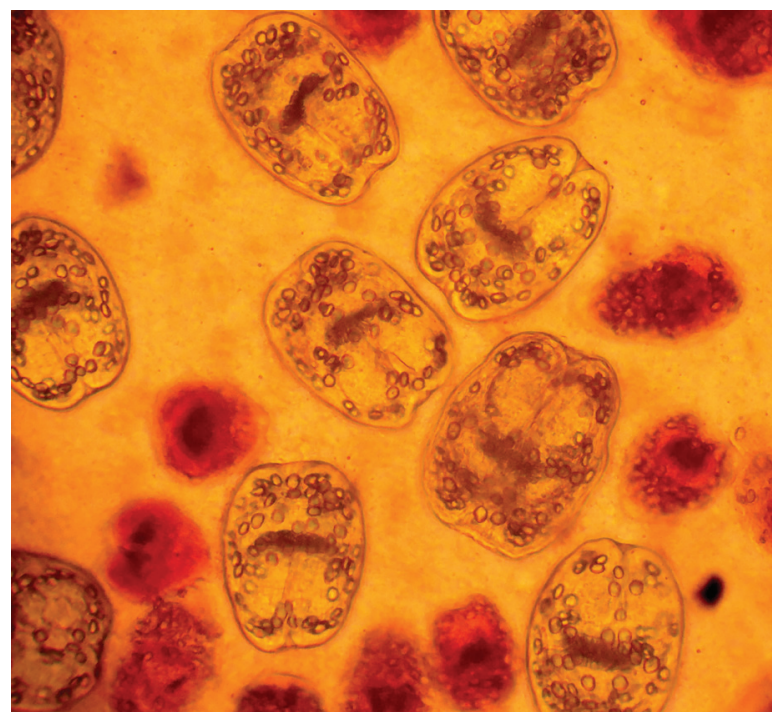

Fig. 2. Viability test after $24 \mathrm{~h}(160 \times)$.

some viable protoscoleces has been preserved. Refrigeration at $4{ }^{\circ} \mathrm{C}$ for 24 and $48 \mathrm{~h}$ did not show high mortality rates.

In addition, even freezing at $-18^{\circ} \mathrm{C}$ for $3 \mathrm{~h}$ remained insufficient to kill all protoscoleces although the mortality rate varied from $30.44 \%$ to $87.28 \%$. The motility of some viable protoscoleces remained positive following this freezing $\left(-18^{\circ} \mathrm{C}\right.$ for $\left.3 \mathrm{~h}\right)$.

However, freezing at $-18^{\circ} \mathrm{C}$ for 6 and $9 \mathrm{~h}$ was found to be very effective in killing all protoscoleces present in the hydatid liquids.

In Tiaret, as in the majority of Algerian slaughterhouses, the absence of incinerators at the slaughterhouse level largely contributed to the spread of hydatidosis since all 
Table 1. Mortality rates of protoscoleces.

\begin{tabular}{|c|c|c|c|c|c|c|c|}
\hline \multicolumn{2}{|r|}{ Experiments } & \multirow{2}{*}{$\begin{array}{c}\text { Temoin } \\
\text { Fresh }\end{array}$} & \multicolumn{2}{|c|}{ Refrigeration } & \multicolumn{3}{|c|}{ Freezing } \\
\hline & & & After $24 \mathrm{~h}$ at $4^{\circ} \mathrm{C}$ & After $48 \mathrm{~h}$ at $4^{\circ} \mathrm{C}$ & $3 \mathrm{~h}$ & $6 \mathrm{~h}$ & $9 \mathrm{~h}$ \\
\hline \multirow[t]{4}{*}{1} & Total number of protoscolex & 419 & 207 & 452 & 810 & 950 & 930 \\
\hline & Number of dead protoscolex & 149 & 92 & 296 & 707 & 950 & 930 \\
\hline & Mortality rate & $35.56 \%$ & $44.44 \%$ & $65.49 \%$ & $87.28 \%$ & $100 \%$ & $100 \%$ \\
\hline & Motility & + & + & + & + & - & - \\
\hline \multirow[t]{4}{*}{2} & Total number of protoscolex & 114 & 914 & 313 & 186 & 720 & 658 \\
\hline & Number of dead protoscolex & 11 & 105 & 63 & 58 & 720 & 658 \\
\hline & Mortality rate & $9.56 \%$ & $12.98 \%$ & $20.13 \%$ & $31.18 \%$ & $100 \%$ & $100 \%$ \\
\hline & Motility & + & + & + & + & - & - \\
\hline \multirow[t]{4}{*}{3} & Total number of protoscolex & 695 & 820 & 566 & 473 & 564 & 490 \\
\hline & Number of dead protoscolex & 73 & 189 & 146 & 144 & 564 & 490 \\
\hline & Mortality rate & $10.50 \%$ & $23.05 \%$ & $25.79 \%$ & $30.44 \%$ & $100 \%$ & $100 \%$ \\
\hline & Motility & + & + & + & + & - & - \\
\hline
\end{tabular}

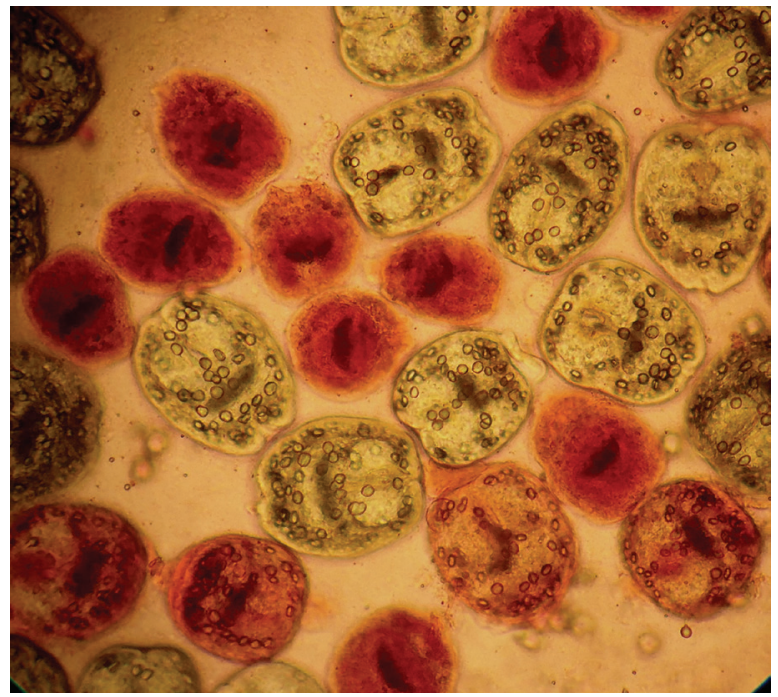

Fig. 3. Viability test after $48 \mathrm{~h}(160 \times)$.

seizures, including those for hydatidosis, are carried by the trucks of communal hygiene to landfill sites, located outside the urban area, where dog access is not difficult. The absence of incinerators in our slaughterhouses contributed significantly to the persistence of hydatidosis, which prompted us to find an alternative to reduce its incidence. This alternative can be the freezing of organs seized for hydatidosis at $-18^{\circ} \mathrm{C}$ for at least 6 $\mathrm{h}$, which will allow sterilization of hydatid cysts before disposal in landfills and even if there will be access to dogs to these cysts, the protoscolex will not be viable and their infesting power will be zero. Thus, freezing was one of the methods recommended by the World

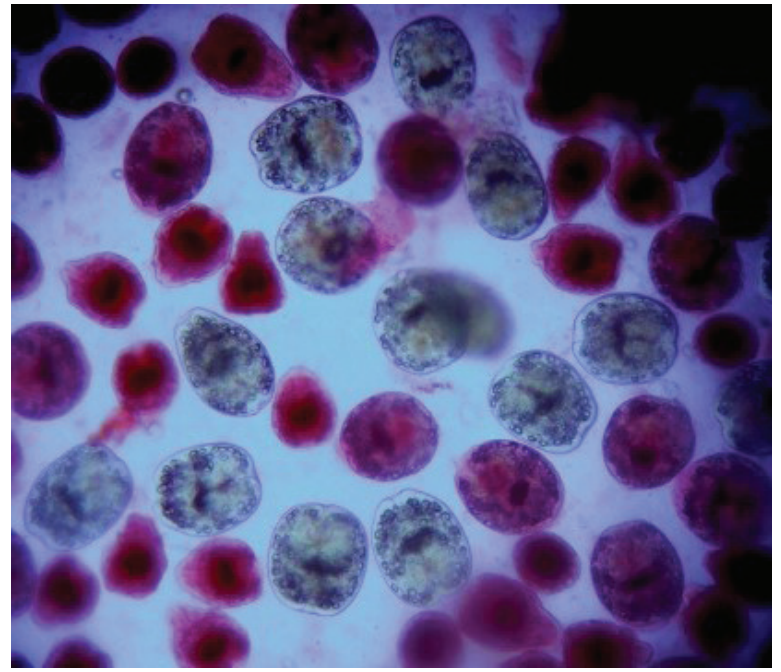

Fig. 4. Viability test at $-18^{\circ} \mathrm{C}$ during $3 \mathrm{~h}(1800 \times)$.

Organisation For Animal Health (OIE) to inactivate hydatid cysts in offal, but with a duration of at least $2 \mathrm{~d}$. This recommendation was adopted in 2011 at a meeting of the ad hoc group and I quote the following passage from Article 8.4.6 procedures for the inactivation of $E$. granulosus (s.1.) cysts in offal for the inactivation of Echinococcus cysts present in offal (OIE, 2011):

One of the following procedures should be used:

- Heat treatment at an internal temperature of at least $80^{\circ} \mathrm{C}$ for $10 \mathrm{~min}$ or equivalent time/temperature;

- Freezing to $-20^{\circ} \mathrm{C}$ for at least $2 \mathrm{~d}$.

The present study has shown that at $-18^{\circ} \mathrm{C}, 6 \mathrm{~h}$ are largely sufficient to inactivate protoscoleces hydatids 


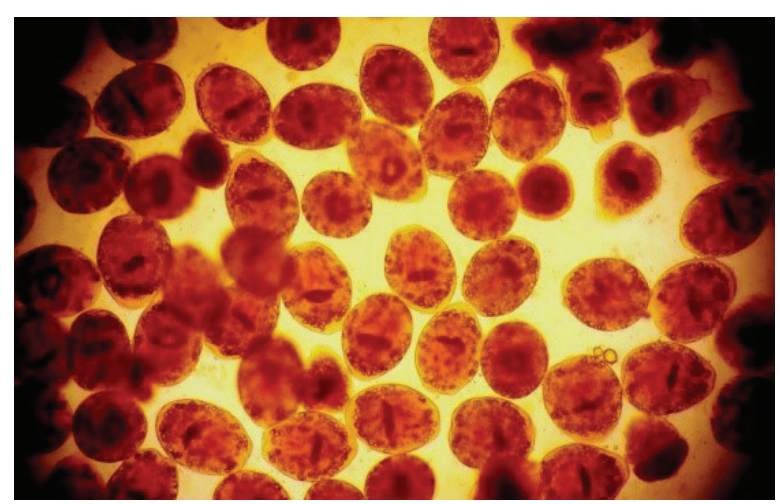

Fig. 5. Viability test after freezing at $-18^{\circ} \mathrm{C}$ during $6 \mathrm{~h}(160 \times)$.

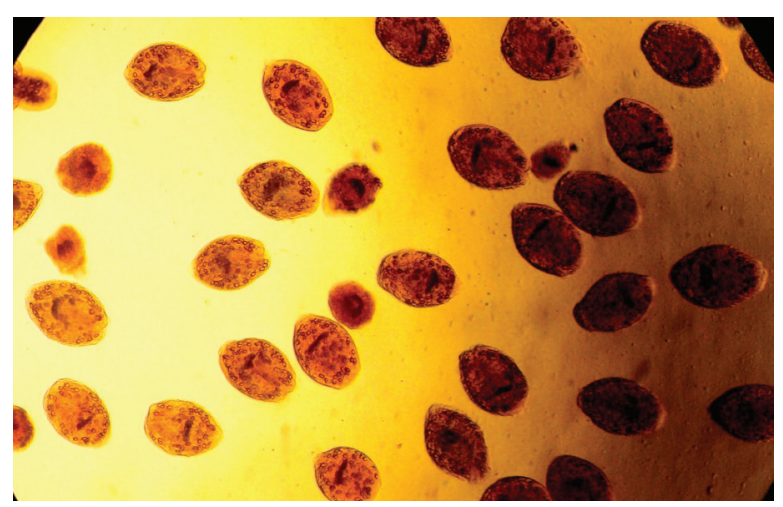

Fig. 6. Viability test after freezing at $-18^{\circ} \mathrm{C}$ during $9 \mathrm{~h}(160 \times)$.

in their viceras and may be a substitute for incineration when this is lacking. Also, our recommendations compared with the OIE can save time and space.

\section{Acknowledgments}

The authors would like to thank the veterinary inspection team at the Tiaret abattoir for their valuable contribution to the collection of hydatid cysts.

\section{References}

Almalki, E., Al-Quarishy, S. and Abdel-Baki, A.A.S. 2017. Assessement of prevalence of hydatidosis in slaughtered Swakny sheep in Riyadh city, Saudi Arabia. Saudi. J. Biol. Sci. 24, 1534-1537.

Aoun, K. and Bouratbine, A. 2007. Actualités épidémiologiques de l'hydatidose en Tunisie. Méd. Maladies. Infect. 37, 40-42.

Benchikh El-Fegoun, M.C., Kohil, K., L'Ollivier, C., Lieu, M., Babelhadj, B., Piarroux, M., Gharbi,
M. and Piarroux, R. 2016. Targeting abattoirs to control cystic echinococcosis in Algeria. Bull. Soc. Pathol. Exot. 109(3), 192-194.

Bentounsi, B., Meradi, S., Ayachi, A. and Cabaret, J. 2009. Cestodes of untreated large stray dog populations in Algeria: a reservoir for herbivore and human parasitic diseases. Open. Vet. Sci. J. 3, 64-67.

Dakkak, A. 2010. Echinococcosis/hydatidosis: a severe threat in Mediterranean countries. Vet. Parasitol. $174,2-11$.

Daryani, A., Sharif, M. and Amouei, A. 2009. Fertility and viability rates of hydatid cysts in slaughtered in the Mazandaran Province, North Iran. Trop. Anim. Health Prod. 41, 1701-1705.

Hasbi, S. and Slioui, B. 2017. Kyste hydatique musculaire lombaire : une localisation rare. À propos d'un cas et revue de la littérature. J. Afr. Hépatol. Gastroentérol. 11(4), 185-186.

Kohil, K., Benchikh El-Fegoun, M.C. and Gharbi, M. 2017. Prévalence du téniasis échinococcique chez les chiens errants dans la région de Constantine, Nord-Est Algérien. Bull. Soc. Pathol. Exot. 110(4), 224-229.

Moro, P. and Schantz, P.M. 2009. Echinococcosis: a review. Int. J. Infect. Dis. 13, 125-233.

OIE. 2011. Ad hoc Group on Zoonotic Parasites (the ad hoc Group) met at OIE Headquarters in Paris on 7-9 December, 2011.

Otero-Abad, B. and Torgerson, P.R. 2013. A systematic review of the epidemiology of echinococcosis in domestic and wildanimals. PLoS Negl. Trop. Dis. 7(6), e2249. doi:10.1371/journal.pntd.0002249.

Sadjjadi, S.M. 2006. Present situation of echinococcosis in the Middle East and Arabic North Africa. Parasitol. Int. 55(Suppl. 1), S197-S202.

Scala, A., Garippa, G., Varcasia, A., Tranquillo, V.M. and Genchi, C. 2006. Cystic echinococcosis in slaughtered sheep in Sardinia (Italy). Vet. Parasitol. 135, 33-38.

Thompson, R.C.A. and McManus, D.P. 2002. Towards a taxonomic revision of the genus Echinococcus. Trends. Parasitol. 18, 452-457.

Torgerson, P.R., Karaeva, R.R., Corkeri, N., Abdyjaparov, T.A., Kuttubaev, O.T. and Shaikenov, B.S. 2003. Human cystic echinococcosis in Kyrgystan: an epidemiological study. Acta. Trop. $85,51-61$. 